\title{
LAS AGUAS
}

\author{
FRANCISCO LÓPEZ MENUDO \\ Catedrático de Derecho Administrativo \\ Universidad de Sevilla
}

\begin{abstract}
RESUMEN
La incorporación de España a la Unión Europea en 1985 coincidió con la aparición de una nueva Ley española de aguas que sustituyó a otra anterior decimonónica. La nueva Ley española actualizó muchas instituciones y técnicas demandadas por las necesidades e intereses surgidos en el pasado, ofreciendo así mucha experiencia en esta materia. Sobre ésta ha incidido el derecho de la Unión Europea, inicialmente limitado a imponer medidas protectoras de la salubridad, ampliando luego sus objetivos hacia el buen estado ecológico general de las aguas y, finalmente, mediante la Directiva Marco 2000/60 ha conseguido penetrar e influir en los múltiples aspectos que componen el derecho de las aguas continentales, la protección de las marítimas y el medio ambiente en general, con sus dos técnicas básicas: la Demarcación Hidrográfica y la Planificación Hidrológica.
\end{abstract}

Palabras clave: salubridad de las aguas; calidad de las aguas; cuenca hidrográfica; demarcación hidrográfica; planificación hidrológica; Directiva Marco 2000/60; vertidos; medio ambiente.

\begin{abstract}
The incorporation of Spain to the European Union in 1985 coincided with the emergence of a new Spanish Water Act which replaced an earlier nineteenth century. The new Spanish Law updated many defendants and techniques for the needs and interests arisen in the past, providing a lot of experience in this area. This has had an impact on the European Union law, initially limited to impose protective measures of health, then expanding its goals to the good overall ecological status of waters and finally through Framework Directive $2000 / 60$ has managed to penetrate and influence in the many aspects that make up the Right of inland waters, maritime protection and the environment in general, with its two basic techniques: the River Basin and water Planning.
\end{abstract}

Key words: wholesomeness of water; water quality; watershed; RBD; water planning; Framework Directive 2000/60; waste; environment. 


\section{SUMARIO}

I. NORMAS EUROPEAS DE NUEVO CUÑO FRENTE A UN DERECHO INTERNO DE VIEJAS RAÍCES. UNA SEMBLANZA DE LOS «INTERESES PROTEGIDOS» EN CADA ETAPA HISTÓRICA.- - II. LA ESPECTACULAR ECLOSIÓN DE LA LITERATURA JURÍDICA SOBRE AGUAS A PARTIR DE LA

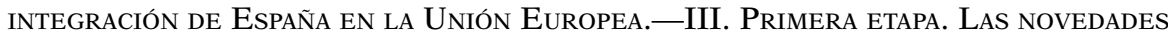
HABIDAS EN LOS PRIMEROS AÑOS DE LA INCORPORACIÓN DE ESPAÑA A LA UNIÓN EUROPEA: 1. La transposición del primigenio derecho europeo sobre aguas: la "perspectiva sanitaria». 2. Las regulaciones españolas internas surgidas al margen del influjo de la normativa comunitaria.-IV. El GIRO DE LA UNIÓN EUROPEA HACIA UNA «PERSPECtiva ECOlÓGICA» EN la PROTECCIÓN de las aguas.-V. La Directiva Marco 2000/60. LA ORDENACIÓN DE LAS AGUAS DESDE UNA PERSPECTIVA GENERAL, INCLUIDO EL ÁMBITO MARINO Y EL MEDIO AMBIENTE: 1. La demarcación hidrográfica como organización. 2. Directiva Marco y planificación hidrológica.-VI. ConcLusión.

I. Normas Europeas de NUEVO CUÑO FRENTE A UN DERECHO INTERNO DE VIEJAS RAÍCES. UNA SEMBLANZA DE LOS «INTERESES PROTEGIDOS» EN CADA ETAPA HISTÓRICA

El 8 de agosto de 1985 publicaba el BOE la Ley de Aguas 29/1985; había sido promulgada seis días antes en Palma de Mallorca. Prácticamente acababa de firmarse en el Palacio Real de Madrid - 12 de junio de 1985- el instrumento de Adhesión del Reino de España a la Comunidad Económica Europea. Por si fuera poca la coincidencia en el tiempo de dos textos de tantísimo alcance —no era la Ley de Aguas una ley cualquiera, aparecía tras más de un siglo de vigencia de la anterior-, ambos establecieron su entrada en vigor el 1 de enero de 1986, o sea, en el mismo día; un hecho tan casual, tan insólito podría decirse, que justificaría sobradamente por sí solo la presencia del clásico tema de las aguas en un volumen como el presente, dedicado a subrayar la incidencia que el derecho de la Unión Europea ha tenido en nuestro ordenamiento interno.

No ha sido pequeña esa influencia en materia de aguas - ya desde la Carta Europea del Agua aprobada por el Consejo de Europa en 1968pero tampoco hay razón para llevarla más allá de sus justos límites, tentación esta a la que puede dar pábulo la ingente bibliografía producida tras el citado acontecimiento. En todo caso, cualquiera que haya sido la verdadera trascendencia del derecho de la Unión Europea dictado en este ramo, un análisis de la cuestión resulta muy oportuno, aunque fuese sólo para despejar este extremo, es decir, si el derecho comunitario ha representado un impacto tan notable como el que sugieren tantos indicios de que ello es así, o si hay que añadir un «ma non troppo» a esa música que nos acompaña desde hace treinta años. 
De manera prioritaria estas líneas se centran en depurar tal cuestión, o sea, valorar o medir el cambio real que ese derecho comunitario ha desplegado en nuestro ordenamiento de aguas. En suma, de lo que se trata es de discernir, de entre esas normas exógenas, cuáles han sido o no decisivas para el derecho hidráulico español, lo que obliga imperativamente a no dejarse arrastrar por la mezcolanza de normas comunitarias e internas con las que suelen presentarse los estudios o tratamientos sobre el tema.

Dada la concreción del objetivo aquí perseguido y el limitado espacio disponible, no es factible descender al detalle de lo regulado por cada norma; y una advertencia aún más principal: no pueden contemplarse aquí todos los aspectos problemáticos que nuestro derecho hidráulico plantea; o sea, no es esto un prontuario del derecho español de aguas hecho a pretexto de conmemorar un aniversario. Por tanto, no será tratado aquí cualquier problema relativo a las aguas, por importante que fuere, si no trae causa directa del derecho comunitario, en coherencia con el fin que motivan estas reflexiones.

El advenimiento del derecho europeo - al cabo, un derecho nuevose produce en este caso sobre un sector del ordenamiento interno tan viejo y consolidado como el que más; un sector cuyo devenir ha debido seguir, por las propias características de su sustrato material —el agua-, los designios de la naturaleza misma, de sus propias leyes físicas, así como las consecuencias derivadas de la civilización y del progreso, con todas sus inherencias consabidas. En suma, un ámbito que al traer causa de un hecho natural y no de una invención intelectual, escapa en gran medida del servilismo a ese albedrío humano que tan frecuentemente gobierna las reglas y las instituciones jurídicas, a veces como absoluto factor determinante.

Por otra parte, se trata de un derecho apegado a unas circunstancias cambiantes que ni siquiera pertenecen a un ámbito espacial concretizado, sino a espacios de dimensiones superiores que son ajenos a los linderos y fronteras artificiales, lo que determina el carácter universal de muchos problemas - por ejemplo, la contaminación - y relativiza al propio tiempo la «originalidad» de las soluciones surgidas de la Unión Europea o de cualquier otra instancia, estatal o supraestatal; pero al propio tiempo, la realidad hidrogeológica de cada territorio de la Unión puede ser acusadamente diferente, lo que hace cuasi quimérica la imposición de medidas iguales a todas ellas.

Por consiguiente, a diferencia de otros sectores jurídicos en los que el derecho comunitario ha podido surgir ex nihilo, bien aportando principios y regulaciones de nuevo cuño o bien enmendando el derecho preexis- 
tente de cada Estado miembro (baste citar principios nuevos como el de confianza legítima, o transformaciones como las operadas en el concepto de servicio público o en el ámbito de la contratación); en cambio, en el ámbito de las aguas, la propia condición de las mismas como bienes físicos que imponen, como antes se dijo, sus propias «leyes naturales» de un modo prácticamente inexorable (la contaminación, las inundaciones, las sequías, la degradación de los hábitats, la realidad de que el agua se arracima en cuencas naturales, y que es transvasable, conservable, consumible, etc.), vienen a condicionar en gran medida las líneas o soluciones que han de ser adoptadas por las normas, apareciendo éstas así como algo bastante predeterminado o previsible por el factum subyacente.

Aplicando lo dicho a nuestro derecho de aguas, ha de señalarse que éste, curtido en su larga trayectoria histórica por mil y un avatares, ha discurrido siempre, como discurren las propias aguas, buscando sus cauces naturales, esto es, las salidas o soluciones que en cada etapa han ido imponiendo los intereses prevalentes, los avances técnicos, los condicionantes del clima y, en suma, los problemas propios de cada etapa. Una visión panorámica del itinerario recorrido a lo largo de siglos permite detectar las prioridades que los poderes constituidos persiguieron en cada momento e incluso de las mutaciones físicas experimentadas por los propios bienes que componen el concepto «aguas» y las variaciones que sus usos y aprovechamientos han tenido en el tiempo. Por ello, sin licencia literaria excesiva puede decirse, con toda naturalidad, que la Historia también está escrita en el agua; en las normas que las han venido regulando y en los principios que han conformado su ordenación a lo largo de su decurso histórico.

Puestos a simplificar al máximo podría decirse que casi han desaparecido los problemas que eran propios de un «derecho de aguas» (rectius: de cuando había agua): obras de defensa, protección contra avenidas, forestación de márgenes, producción de energía eléctrica, pesca, navegación, desecación de marismas y lagunas; y hemos pasado a un "derecho de la escasez de agua» (transvases, planificación hidrológica, desalación, reutilización de aguas de vertidos, reserva de caudales ecológicos, acuíferos sobreexplotados, declaraciones de sequía, contaminación de caudales, mortandad de fauna y flora, etc.), todo ello derivado de un hiperconsumo y una contaminación desconocidos en la antigüedad.

Para ratificar el anterior aserto será suficiente señalar con suma brevedad algunos hitos esenciales de la historia de nuestras aguas, desvelando en cada caso los «intereses protegidos» subyacentes. Así, se comprueba cómo en una economía marcadamente agraria como la de Roma su derecho se ocupó de regular meticulosamente la figura de la locatio- 
conductio -emparentada con las actuales concesiones-y del canon por el aprovechamiento de las mismas llamado vectigal, dado que en Roma las aguas eran res extra commercium ${ }^{1}$. También el Derecho antiguo se ocupó profusamente de figuras de ascendencia romana como la alluvio, la avulsio, la insula in flumine, el alveus derelictus ${ }^{2}$, fenómenos que aunque aún se sigan dando en la actualidad evocan una naturaleza asilvestrada, no dominada por la mano del hombre, situándose el interés prevalente en la pura clave fundiaria de quienes serán a la postre los titulares de los predios tras las mutaciones operadas por las corrientes embravecidas o desmandadas.

Reflejo de una sociedad primitiva y sedentaria es el que se extrae de las Partidas al subrayar como intereses prevalentes los de los propietarios ribereños, tanto al uso y al disfrute de las márgenes colindantes con las aguas - por derecho de accesión- con verdadera exaltación de su libérrimo derecho a construir defensas contra las aguas como al aprovechamiento prácticamente libre de éstas, sólo limitado por el mejor derecho de tercero en el tiempo ${ }^{3}$ y el deber de no dificultar la navegación ni la pesca y su tráfico comercial ${ }^{4}$, que serán los nuevos intereses emergentes que acabarán por imponerse. En efecto, la prevalencia del interés sobre la pesca fluvial así como por la navegación y la flotación, fue de tal nivel que sería plasmado luego en la Ley de Aguas de $1879^{5}$. El siguiente eslabón de esta cadena de intereses cambiantes constituye uno de los grandes hitos de la historia de las aguas: la demanialización, en el derecho de Castilla, de todas las aguas profluens ${ }^{6}$. Fue decisivo para ello el impulso final de la Ilustración ${ }^{7}$, pues su espíritu fraguó en dos dis-

1 C. Pérez Gómez (1966), Régimen jurídico de las concesiones administrativas en el Derecho romano, Madrid: Dikinson, pág. 96.

2 Por cierto, aún vigentes por remisión del vigente TR de la Ley de Aguas de 2001 (art. 8) a la legislación civil (art. $370 \mathrm{Cc}$ )

3 «... pero debe eso ser fecho de manera que el corrimiento del agua non se embargue al otro, más que la aya libremente según que era antes acostumbrada a correr...». Partida III, Título XXXII, Ley 18.

4 Partida III, Título XXXVIII, Leyes $6^{\mathrm{a}}$ y $8^{\mathrm{a}}$.

5 Esa pesca fluvial, que nos trae a la imaginación unos cauces y aguas muy distintos de los actuales, es tratada por los textos antiguos como de interés prioritario, llegando a protagonizar un duro pulso contra la «casta» privilegiada de los propietarios ribereños —una colisión parangonable a la bien conocida entre agricultores y ganaderos-, pugna esta que en su Informe de 1794 decantó el pensamiento de G. M. Jovellanos en favor de los pescadores (Obras Completas, tomo 50, pág. 480).

6 Es decir, las aguas superficiales de todos los cauces, abstracción hecha de la navegabilidad o flotabilidad. La alusión hecha en el texto al Derecho castellano deja a salvo el régimen de corte regaliano que ya era característico de la Corona de Aragón y el Reino de Valencia. Vid. F. López Menudo (2013), La vieja cláusula "sin perjuicio de tercero» y la Administración del porvenir, Granada: Comares, pág. 25.

7 Así, resulta obligado citar la Ordenanza de Corregidores de 13 de octubre 1749 y en la Instrucción de Corregidores de 1788. 
posiciones que aunque no muy renombradas son posiblemente las más importantes del derecho español de aguas: la Real Orden de 14 de marzo de 1846 que vino a exigir autorización Real para poder aprovechar aguas de los cauces y la Ley de 24 de junio de 1849, suscrita por Bravo Murillo, imponiendo la servidumbre forzosa de acueducto y desmontando así el sistema establecido durante siglos de considerar las riberas como del pleno dominio de los propietarios adyacentes.

La Ley de Aguas de 1879 operó con esa herencia tan preciada y es muestra de ello tanto la enorme atención que prestó a las servidumbres, tanto naturales como legales, y a los usos y aprovechamientos, ya bajo el signo de la demanialidad. Aprovechamientos no reducidos, como otrora, a la pesca y la navegación, sino sobre todo a los riegos. Pero además de ello la Ley incorpora nuevos puntos de atención, o sea, de intereses propios de su época (abastecimiento de poblaciones, de ferrocarriles, puentes, concesiones de aprovechamiento para industria...) objetivos todos ellos facilitados por su bien nutrido cuadro de servidumbres forzosas. Pero en la Ley luce sobre todo la prolija regulación que hace de las Comunidades de Regantes. En fin, puede concluirse, con toda la simplificación que ello supone, que el interés dominante de la Ley de Aguas de 1879 fue el aprovechamiento de las aguas superficiales para riegos.

El largo trayecto que media entre la Ley citada y la de 1985 —más de un siglo- está jalonada de disposiciones importantes, cada una de las cuales permite ver la aparición de problemas e intereses nuevos, de los que, obviamente, sólo cabe dejar aquí muy somera constancia. Por ordenar de algún modo tan largo período cabe decir que desde la existencia de la Ley de 1879 hasta el final del siglo XIX destacan dos líneas de actuación cuyo germen ya se encontraba en dos breves apartados de aquella Ley: la incipiente preocupación por la construcción de canales y pantanos de interés público ${ }^{8}$ y por la desecación de lagunas y terrenos pantanosos y encharcados ${ }^{9}$.

Es insuperable el valor simbólico que tiene la primera disposición aparecida en el siglo xx: la también primera norma que se ocupa del «enturbiamiento e infección» de las aguas públicas ${ }^{10}$, siendo por tanto la cabecera de la enorme serie de disposiciones sobre vertidos, tanto en-

\footnotetext{
8 Ley de 27 de julio 1883 y RD 9 de abril de 1885 .

9 RD 21 de marzo 1895. Una actividad proscrita en la actualidad pero que ha de tratar de comprender en el contexto de la época, cuando la ciencia y la medicina no habían logrado conjurar los peligros inherentes a tales lugares. Es de obligada cita la posterior Ley de 24 de julio de 1918 relativa a la desecación de lagunas, marismas y terrenos pantanosos.

10 RD de 16 de noviembre de 1900, Reglamento sobre enturbiamiento e infección de aguas públicas y sobre aterramiento y ocupación de sus cauces con los líquidos procedentes del lavado de minerales o con los residuos de las fábricas.
} 
dógenas españolas como comunitarias. Y al término de la primera década de dicho siglo emerge también, ya imparablemente, el interés por el alumbramiento de las aguas subterráneas, hasta entonces «dormidas», como podría decirse plásticamente ${ }^{11}$; para seguir después dando paso al objetivo de construir obras hidráulicas - que ya abordaron las incipientes normas decimonónicas más arriba anotadas- bajo la cobertura de la Ley General de Obras Públicas de 1877 y ahora con la específica Ley Gasset de 7 julio de 1911 sobre construcciones hidráulicas con destino a riegos.

Desde esta última Ley, sobre auxilios del Estado a la iniciativa privada, hasta la contienda civil española sobresale entre todo, de forma superlativa, la creación de las Confederaciones Sindicales Hidrográficas por Real Decreto de 5 de marzo de 1926. Ellas representaron los intereses confluyentes que venían fraguándose desde la Ley de Aguas (instrumentos de una política favorecedora de los riegos, de las obras hidráulicas y de participación de los usuarios) y adoptaron la cuenca natural como el sustrato material de actuación. ¿Quién pudo pensar entonces que se convertirían ahora en las demarcaciones hidrográficas de ascendencia europea?...

La etapa comprendida entre la postguerra y la Ley de Aguas de 1985 ofrece un panorama en el que se advierten como intereses subyacentes los propios del desarrollismo: explotación de aguas subterráneas, construcción de embalses y demás obras hidráulicas, potenciación de las comunidades de regantes, potabilización de las aguas para abastecimiento de poblaciones, repoblación forestal... apreciándose a su vez los problemas generados por tal caldo de cultivo, resumibles en una sola palabra: contaminación; vertidos por doquier, sin un marco regulador acorde con la magnitud del fenómeno ${ }^{12}$.

La Ley de Aguas 29/1985 de 2 de agosto, en la antesala misma de nuestra entrada en la Comunidad Europea, centra su interés en cuatro puntos fundamentales: la demanialización de las aguas subterráneas y por ello la proclamación como dominio público del Estado de todas las aguas, la organización administrativa hidráulica adecuada para dar respuesta al hecho de las autonomías, la planificación hidrológica y la necesidad de controlar los vertidos y atajar los casos de sobreexplotación y contaminación de acuíferos; todos ellos objetivos e intereses nuevos no

11 RRDD de 28 de junio, 11 y 23 de julio de 1910.

12 Comparadas con esas cotas del desarrollismo señalado resulta clamorosa la ausencia de unas disposiciones proporcionadas en materia de vertidos más allá de lo dispuesto con extraordinaria parquedad por el Reglamento de Policía de aguas y sus cauces, de 1958 y por las numerosas normas que de forma sistemática se dirigían a paliar la situación de los ríos guipuzcoanos. 
contemplados ni por asomo en la Ley de 1879 y que la nueva Ley impone como "medidas indiscutibles desde el punto de vista científico y recogidas en su doctrina por organismos e instancias internacionales», pero sin aludir expresamente a los órganos comunitarios europeos. También aparecen tímidamente en la Ley objetivos nuevos que más tarde serán objeto de mayor atención: la reutilización de aguas depuradas y la protección de las zonas húmedas.

Todos los problemas, objetivos y regulaciones que han quedado descritos son autóctonos, aunque eventualmente algunos de ellos hayan sido luego incididos por normas comunitarias, como las que serán ya examinadas a partir de este punto.

Sin embargo, parece oportuno hacer un breve alto en el camino para valorar el impacto que ese cuasi-mágico año 1986 en materia de aguas produjo en la doctrina científica.

II. LA ESPECTACULAR ECLOSIÓN DE LA LITERATURA JURÍDICA SOBRE AGUAS A PARTIR DE LA INTEGRACIÓN DE ESPAÑA EN LA UNIÓN EUROPEA

Ciertamente, esa llamativa coincidencia de la entrada en vigor de la Ley de Aguas y la adhesión de España a la Comunidad Europea se vio reforzada con un tercer factor que ahora es oportuno destacar: fue el momento en el que el derecho comunitario relativo a las aguas empezó a tomar cierto cuerpo; y si a esta tríada de circunstancias se añade como cuarto factor concomitante la expansión del derecho medioambiental con el que las aguas guardan tan íntima conexión, sólo ello puede explicar el espectacular cambio de rumbo del derecho de aguas en la doctrina científica, la eclosión de un interés inusitado por el derecho hidráulico, antes desconocido. Por tanto, valgan al menos unas palabras sobre algo tan notable y tan adherido a la cuestión principal de la que aquí se trata, unas pinceladas sobre la doctrina, aliviadas de la carga del dato bibliográfico detallado, pues lo contrario haría inviable el empeño.

Como venía ocurriendo desde siempre con las denominadas "propiedades especiales», el derecho de aguas carecía de un tratamiento doctrinal acorde con su importancia social y económica y su complejidad jurídica, muy superior a la de otros sectores. En este aspecto doctrinal, ciertamente sorprendente por su orfandad, sólo contaban algunas obras luminosas $^{13}$. Pero la verdadera referencia científica del sector durante

13 Tal como la de C. Franouet y Bertrán (1859), Proyecto de Código General de Aguas..., una espléndida conferencia de Latour Brotóns (1955), Antecedentes de la primitiva Ley de Aguas, más un útil Manual práctico de aguas (1909) de G. DE MonTElLá y unos Comentarios a la 
cuarenta años (1960-1999) estuvo encarnada por Sebastián MartínRetortillo Baquer, ferviente estudioso de la materia y dinamizador de todo cuanto con ella se relacionaba ${ }^{14}$.

Como antes se dijo, 1986 produjo un desbordamiento inusitado del interés por el mundo de las aguas continentales y ya en ese mismo año comienzan a aparecer obras importantes de carácter general ${ }^{15}$. A partir de entonces surgieron ya las obras especializadas en aspectos sectoriales que fueron encontrando conexión en mayor o menor medida con lo regulado por el derecho europeo. El panorama ofrece un auténtico mar de obras y autores, prácticamente inmanejable. Aun a riesgo de incurrir en omisiones significativas nos atrevemos a citar algunos de ellos; y puede afirmarse con seguridad que en esta nueva etapa es Antonio Embid Irujo quien ocupa el preeminente lugar que en la etapa anterior ocupara Sebastián Martín-Retortillo. Autor aquel de una obra de extensión y variedad muy notables ha venido impulsando el estudio del derecho de aguas en los últimos años ${ }^{16}$. Y también resulta obligado destacar a ciertos autores que con alguna insistencia han seguido la pista a problemas propios de este ámbito ${ }^{17}$.

Ley de Aguas de 1879 que este mismo autor elaboró junto a MAssó Escofet (1956). Posteriores fueron algunos artículos sueltos como el de JoRdANA DE Pozas (1962), «La evolución del Derecho de Aguas en España y en otros países», y la atención que le prestó A. GuAita (1969), Tratado de Derecho administrativo especial. Destacada mención merecen los brillantes estudios de A. NiETo sobre aguas subterráneas, el último de los cuales elaboró precisamente para el Primer Congreso Nacional del Derecho de Aguas (1984).

14 Sus numerosos artículos, dirección de libros colectivos, Congresos...; su discurso de entrada en la Real Academia de Jurisprudencia y Legislación (1995); y desde luego su admirable iniciativa de editar el libro La Ley de Aguas de 1866 (1960), abriendo con él las puertas a un mundo culto y entendido en la materia como el que estuvo detrás de aquella Ley. Condensó su sabiduría sobre el tema en su voluminoso Derecho de Aguas, 1997, ya en plena integración de España en la CEE.

15 Gallego Anabitarte, Menéndez Rexach y Díaz Lema (1986), El Derecho de Aguas en España, que fue seguida casi coetáneamente por otra igualmente general de GonzÁLEz PÉREZ, Toledo Jáudenes y Arrieta Álvarez (1987), Comentario a la Ley de Aguas.

16 Así, por ejemplo, las Jornadas anuales de Derecho de Aguas y la influencia de su figura en el área iberoamericana; así como el estudio de los problemas más relevantes que han ido apareciendo. Pueden citarse estudios y libros colectivos sobre abastecimiento urbano y depuración, obras hidráulicas y su financiación, planificación hidráulica, sobreexplotación de aguas subterráneas, gestión del agua y descentralización, agua y energía, agua y agricultura, demarcaciones y cuencas hidrográficas, autorizaciones, concesiones y mercados del agua, e incluso un Diccionario de Derecho de Aguas que logró coordinar en 2007.

17 Por ejemplo, A. MenÉndez Rexach, en cuya dedicación al tema sobresalen sus estudios sobre planificación hidrológica y territorial; A. FANLO LORAS y sus preocupaciones por temas organizativos y competenciales amén de los transvases; I. CARO-PATÓN CARMONA, autora de un abanico de temas de los que pueden destacarse los relativos al tratamiento estatutario autonómico y la Directiva Marco de aguas y su transposición al derecho español; B. Situain Mendia, con sus estudios, entre otros, sobre reutilización de aguas, protección de las superficiales y tarificación de los servicios. Notable es igualmente la aportación de F. Delgado Pigueras, desde la perspectiva protectora y su conexión con el medio ambiente; F. GARCía RUBIo, en la conjunción entre aguas y urbanismo. Monografías importantes como las de $M^{\mathrm{a}}$ C. ORTIZ DE TENA (1994) sobre la planificación hidrológica, obra temprana sobre el tema que constituyó su tesis doctoral a 
III. Primera Etapa. Las novedades habidas EN los PRimeros años DE LA INCORPORACIÓN DE ESPAÑa A LA UNIÓN EUROPEA

\section{La transposición del primigenio derecho europeo sobre aguas: la "pers- pectiva sanitaria»}

Con la firma del Acta de Adhesión en 1985 el Reino de España asumió la obligación de poner al día su derecho interno a la luz del derecho comunitario y derivado hasta entonces emitido. Esto no supuso una carga gravosa en el sector concreto de las aguas; de una parte porque el Tratado constitutivo de la Comunidad Económica Europea (1957) no contenía una referencia directa al tema de las aguas continentales o marítimas, sino unos principios muy genéricos relativos al medio ambiente bajo cuya cobertura fue dictándose lo que podríamos denominar como la «protohistoria» del derecho comunitario en materia de aguas, Directivas en su mayoría dirigidas a la protección de la salud de las personas, es decir, lo que pudiera llamarse, tomando la conocida expresión de Tomás Ramón Fernández referida a cierta fase del urbanismo decimonónico, una «perspectiva sanitaria». Así, varias directivas sobre aguas potables destinadas al consumo humano ${ }^{18}$, sobre la calidad de las aguas de baño ${ }^{19}$, utilización de lodos de depuradora en agricultura ${ }^{20}$, calidad de las aguas aptas para la cría de peces y de moluscos ${ }^{21}$, así como protección de aguas subterráneas contra la contaminación por sustancias peligrosas $^{22}$.

Estas directivas «sanitarias» o relativas a la salubridad fueron dictadas con anterioridad al Acta de Adhesión de España y, por tanto, a

la que han seguido otros trabajos suyos; S. DEL SAZ, sobre aguas subterráneas (1990), y J. M. DE la CuÉtara sobre el mismo tema (1989), A. Esquerra Huerva sobre el régimen jurídico de las obras hidráulicas (2007), A. DE MARcos FernÁNDEZ en torno al principio de unidad de cuenca y las demarcaciones hidrográficas, A. SÁNCHEz BLANCO, en clave de conexión entre la normativa europea sobre aguas y el Derecho interno. Y, en fin, otros autores atentos a las aguas de cuyos nombres es justo hacer al menos relación: R. Martín Mateo, G. Ariño Ortiz, C. Horgue Baena, B. Marina Jalvo, I. Gallego Córcoles, J. Agudo González, L. Mellado Ruiz. Finalmente, especial mención merece el catedrático de Derecho Civil J. L. Moreu BALLONGA, prolífico autor de trabajos sobre aguas, especialmente desde la perspectiva del derecho histórico y de los problemas iusprivatistas que siguen incidiendo sobre el derecho de aguas.

18 Directiva 75/440 de 16 junio, Directiva 79/869 de 9 de octubre, Directiva del Consejo 80/778 de 15 de julio, Directiva 81/858 de 19 de octubre sobre aguas potables destinadas al consumo humano.

19 Directiva del Consejo 76/160 de 8 de diciembre sobre calidad de las aguas de baño.

20 Directiva 76/464 de 4 de mayo sobre la utilización de lodos de depuradora en agricultura.

21 Directiva 78/659 de 18 de julio, Directiva 79/923 de 30 de octubre.

22 Directiva 80/68 de 17 de diciembre, que fue incorporada seis años después al Reglamento de Dominio Público Hidráulico y luego derogada por la Directiva Marco de 2000; a la que hay que añadir tres directivas concretamente referidas a vertidos de mercurio (82/176 de 22 de marzo), hexaclorocicloexano (84/491 de 9 de octubre) y cadmio (85/513 de 29 de junio). 
la Ley de Aguas de 1985, aunque la doctrina ya se ocupaba de aquellas con toda normalidad ${ }^{23}$ pudiendo presumirse que durante la elaboración de dicha Ley ya se tuvieran en cuenta dada la atención que por primera vez fue prestada al tema de los vertidos desde una norma de tal rango. Pero no fueron incluidas dichas directivas entre las de urgente o prioritaria transposición y aunque este dato sugiere que el proceso no fue especialmente accidentado, ello no permite ignorar que el Tribunal de Luxemburgo llegó a dictar sentencias declarando incumplimientos por no haber sido adoptadas las disposiciones y medidas correspondientes, ora en general, ora para lugares concretos ${ }^{24}$; mas creemos que ello no merma la validez de la apreciación general que va quedando expuesta. Las correspondientes transposiciones fueron produciéndose por goteo, en los inmediatos años posteriores; la última por RD 1138/199025.

Sin embargo, los años siguientes al Acta de Adhesión de España ofrecen, en cuanto a la normativa europea, un período de cierta languidez y ello pese al nuevo Tratado de la Unión firmado en Maastrich (1992) que intensificó notablemente las previsiones en materia de medio ambiente (art. 130), ya que las directivas que se aprueban por esta época son escasas y siempre incidentes sobre la potabilidad de las aguas destinadas al consumo humano y el tratamiento de las residuales ${ }^{26}$, disposiciones comunitarias que generan en el derecho interno correlativas normas de obligada cita pero en cuya glosa no es posible detenerse aquíi ${ }^{27}$.

23 Así, por ejemplo, en la obra de J. González Pérez et al., Comentarios a la Ley de Aguas, antes citada, aparecida recién entrada en vigor la Ley de 1985, se da cumplida cuenta de las directivas sobre vertidos que venimos de exponer y ello se hace con toda naturalidad en el seno de los comentarios a los artículos más significativos de dicha Ley —92 y 94- sobre vertidos, lo que evidencia la imbricación que tan precozmente se advertía entre el derecho comunitario y dicha Ley de Aguas.

24 Así, SSTJCE 12-2-1998 (C-92/96), 1-10-1998 (C-71/97), 25-11-1998 (C-214/96), 13-4-2000 (C-274/98), 16-1-2003 (C-29/02), 25-11-2003 (C-278/01), 8-9-2005 (2005/256 y 260), 15-12-2005 (2005/410), 15-4-2007 (2007/74).

25 No cabe dejar aquí cumplida cita de tales directivas, dado que tres de ellas fueron derogadas luego por la Directiva Marco 2000/60 de 23 de octubre y porque las disposiciones españolas que las transpusieron no están vigentes, sino sustituidas por otras posteriores de las que sí se dará razón.

26 Directiva 2009/90 de la Comisión de 31 julio en la que se establecen especificaciones técnicas del análisis químico y el seguimiento de las aguas, directiva 91/271 del Consejo de 21 de mayo sobre tratamiento de aguas residuales, Directiva 91/676 de 12 de diciembre sobre protección de aguas contra contaminación producidas por nitratos procedentes de fuentes agrarias, Directiva 96/61 del Consejo de 24 de septiembre sobre prevención y control integrado de la contaminación, Directiva 96/82 del Consejo de 9 diciembre relativa al control de los riesgos inherentes a los accidentes graves en los que intervengan sustancias peligrosas, Directiva 98/83/ $\mathrm{CE}$ del Consejo de 3 de noviembre sobre calidad de las aguas destinadas al consumo humano.

27 RD-Ley 11/1995 de 28 diciembre por el que se establecen las normas aplicables al tratamiento de las aguas residuales urbanas, RD 261/1996 de 16 de febrero sobre protección de las aguas contra la contaminación producida por los nitratos procedentes de fuentes agrarias, 
La última de las directivas anteriormente citada (98/83 de 3 noviembre), que sustituyó a otra anterior (80/78) relativa a la protección de la calidad de las aguas destinadas al consumo humano, fue precisamente la que puso fin a la tanda de directivas «sanitarias» anteriores al momento en que la propia UE aprobara la Directiva Marco 2000/60 de 23 de octubre con la que se abría a otros objetivos, aunque bien es verdad que esa política de protección de la salubridad de las aguas nunca ha sido abandonada, debiendo ser resaltadas al respecto cuatro directivas a lo largo de 2006, o sea, ya transcurrido más de un lustro desde la aparición de la Directiva Marco, con las que la UE aborda las distintas vertientes del problema de la contaminación en los que ya habían incidido las directivas primigenias; así, en el ámbito de las aguas de baño ${ }^{28}$, en el de la calidad exigida a las aguas continentales para ser aptas para la vida de los peces ${ }^{29}$ y para la cría de moluscos — aplicándose ésta a las aguas costeras y salobres ${ }^{30}$ - y la dirigida a la protección de las aguas subterráneas contra la contaminación y el deterioro ${ }^{31}$. Dos años después fue aprobada la importante Directiva 2008/105 de 16 diciembre del Parlamento de la UE y del Consejo estableciendo normas de calidad ambiental con carácter más general ${ }^{32}$. Por consiguiente, quede en este punto cerrada esta primera época del influjo del derecho europeo, básicamente constreñido a los aspectos de salubridad, al objeto de abrir un nuevo capítulo o etapa que tiene su propio sello, como veremos.

\section{Las regulaciones españolas internas surgidas al margen del influjo de la normativa comunitaria}

Es oportuno resaltar que mientras ocurría todo lo que venimos de relatar sobre la incidencia de la Comunidad Europea en nuestro ordenamiento, el legislador español no se ocupó sólo de transponer las directivas comunitarias, sino que además produjo una serie de normas «endógenas» de gran utilidad y calado, tales como los reglamentos eje-

RD 509/1996 de 15 de marzo de desarrollo del Real Decreto Ley 11/1995, de 28 de diciembre, por el que se establecen las normas aplicables al tratamiento de las aguas residuales urbanas.

28 Directiva 2006/7 de 15 de febrero del Parlamento de la UE y del Consejo que deroga la Directiva 76/160 más arriba citada y cuyos objetivos son los de reducir y prevenir la contaminación de las aguas de baño e informar a los europeos sobre su grado de contaminación. Su transposición fue realizada por el RD 1341/2007 de 11 de octubre.

29 Directiva 2006/44 de 6 de septiembre del Parlamento y del Consejo.

30 Directiva 2006/113 de 12 de diciembre del Parlamento y del Consejo.

31 Directiva 2006/118 de 27 de diciembre del Parlamento y del Consejo; transposición por RD 1514/2009 de 2 octubre (última modificación RD 16 de diciembre 2015).

32 Su transposición se hace por el RD 60/2011 de 21 de enero. La Directiva fue modificada a su vez por la 2013/39 del Parlamento y del Consejo de 12 de agosto 2013. 
cutivos de la Ley de Aguas: Reglamento de Dominio Público Hidráulico, Reglamento de la Administración Pública del Agua y de la Planificación Hidrológica, así como el Real Decreto que definía los ámbitos territoriales de los Organismos de Cuenca y de los Planes Hidrológicos ${ }^{33}$. Pero sobre todo debe ser subrayado con grueso trazo que en esta etapa se dictan hasta cuatro leyes sobre la explotación del acueducto Tajo-Segura $^{34} \mathrm{y}$ otras sobre actuaciones en materia de aguas en Tarragona ${ }^{35} \mathrm{y}$ transferencia de volúmenes de la cuenca del río Guadiaro a la cuenca del Guadalete ${ }^{36}$ que abren la llamada "guerra del agua» entre las comunidades autónomas afectadas, aunque sin llegar a la virulencia que posteriormente suscitaría el proyectado transvase del Ebro que, tras una verdadera batalla, no se produjo, para lo que hubo que ser derogado el Plan Hidrológico Nacional en lo concerniente al mismo, optándose por medidas de desalación y reutilización de aguas residuales ${ }^{37}$.

Pero sobre todo, durante el año 1989 quedan constituidas como Organismos de Cuenca las Confederaciones Hidrográficas existentes desde 1926 ${ }^{38}$; y casi una década después son aprobados los Planes Hidrológicos de Cuenca ${ }^{39}$. Este hito y este logro debe quedar fijado nítidamente como algo que sucede con anterioridad a la reforma de la Ley de Aguas 46/1999 e, igualmente, antes de que el derecho europeo cogiera nuevos vuelos a partir del año 2000. Por tanto, se trata de unas acciones absolutamente autóctonas dado que el derecho comunitario ni siquiera había rozado aún estos grandes asuntos y, en consecuencia, ni las normas que constituyeron los organismos de cuenca ni aquella que aprobó diez años después los planes hidrológicos de tales cuencas, hacen la más mínima mención a las normas comunitarias, ni siquiera a pretexto de dejar alguna cita sobre esa «perspectiva sanitaria» a la que el derecho comunitario se había dedicado hasta esa fecha.

33 Respectivamente, RD 849/1986 de 11 de abril, modificado en sucesivas ocasiones; RD 927/1988 de 29 julio, también modificado después varias veces; RD 650/1987 de 8 de mayo.

34 Ley 21/1971 de 19 de junio sobre el aprovechamiento conjunto Tajo-Segura, Ley 52/1980 de 16 de octubre de Regulación del Régimen Económico de la explotación del acueducto TajoSegura, Ley 13/1987 de 17 de julio de Derivación de Volúmenes de Agua de la Cuenca Alta del Tajo a través del Acueducto Tajo-Segura, con carácter experimental con destino al Parque Nacional de las Tablas de Daimiel, Real Decreto Ley 8/1995 de 4 de agosto por el que se adoptan medidas urgentes de mejora del aprovechamiento del trasvase Tajo-Segura.

35 Ley 18/1981 de 1 de julio sobre actuaciones en materia de aguas en Tarragona.

36 Ley 17/1995 de transferencia de volúmenes de agua de la cuenca del río Guadiaro a la cuenca del río Guadalete.

37 Real Decreto Ley 2/2004 de 18 de junio.

38 RRDD de 21 julio de 1989 por los que se constituyen los organismos de cuenca Confederación Hidrográfica del Júcar (924), Segura (925), Guadalquivir (926), Tajo (927), Guadiana (928), Duero (929), Norte (930), Ebro (931).

39 RD 1664/1998 de 24 de julio. 


\section{El GiRo de LA UNIÓN EUROPEA HACIA UNA «PERSPECTIVA ECOLÓGICA» EN LA PROTECCIÓN DE LAS AGUAS}

Como ha quedado dicho supra, el Tratado de Maastrich (1992) no generó de inmediato una política protectora de las aguas muy distinta de la que hasta entonces venía desarrollándose. Sin embargo, en el propio texto del nuevo Tratado anidaba una nueva filosofía que acabaría asentándose ocho años después con la Directiva Marco del año 2000. En efecto, en Maastrich salen las aguas de una vagarosa idea de «medio ambiente» y adquieren sustantividad propia al postular dicho texto, entre las medidas conducentes a la protección y mejora de la calidad del medio ambiente, salud de las personas y utilización racional de los recursos naturales (art. 130.1), la gestión de los recursos hídricos. Y en este mismo artículo, re-numerado como 175.2 en virtud del Tratado de Niza de 26 de febrero de 2001, queda reforzado el protagonismo de las aguas para la consecución de los objetivos antes señalados, pues las medidas que se propugnan se refieren ahora a «la gestión cuantitativa de los recursos hídricos o que afecten directa o indirectamente a la disponibilidad de dichos recursos», fórmula que refleja una clara preocupación tanto por la cantidad de los recursos hídricos necesarios como por la «disponibilidad» de los mismos, esto es, porque ofrezcan la calidad o aptitud precisa para su uso.

Surge así una especie de doble objetivo (incremento de la cantidad de agua disponible pero con niveles de protección elevados) tan ligados entre sí que en puridad constituyen sólo uno, pues, lógicamente, su interdependencia es de tal grado que al cabo se confunden y fusionan. Claro es: la cantidad - mayor o menor- de agua es factor determinante del grado de calidad ecológica de una corriente o de un cauce; y a su vez, es la calidad la que hace posible que las masas de agua puedan ser útiles para la mayoría de sus destinos posibles ${ }^{40}$.

Este giro del derecho europeo hacia la defensa ecológica del medio, expresado en sus inicios en términos que no pueden ser precisamente calificados como rotundos, luce en cambio con toda claridad en el derecho interno español, primero por la Ley de Aguas de 1985 y sobre todo

40 Por ello, pensar en la posibilidad de optar preferencialmente por uno de esos dos objetivos con descuido del otro (por ejemplo, la búsqueda de nuevos caudales o aprovisionamientos con olvido de medidas contra la contaminación; o viceversa) es una hipótesis inválida en su propia raíz. Una vez más se constata cómo en este microcosmos jurídico cuya sustancia es el agua, la propia naturaleza de las cosas — nunca mejor dicho: la peculiar naturaleza del elemento- conduce a descartar las soluciones irrazonables, reduce los márgenes de discrecionalidad e incluso apunta o señala el camino a seguir como el más idóneo a la vista de los factores concurrentes. 
luego por obra de la Ley 46/1999 de 13 de diciembre de Reforma de la Ley de Aguas, ley meritoria a la que, por tanto, hay que atribuir la generación del primer impulso significativo de esta óptica ecológica añadida a la política básica de incrementar los recursos hídricos por todos los medios posibles que era la que imperaba en el derecho interno hasta entonces. Así, el legislador de la reforma de 1999, por una parte mejora los aspectos del derecho de aguas que pudiéramos denominar «clásicos» en orden a favorecer el fomento del ahorro y la mejor gestión del bien (administración pública del agua, comunidades de regantes, planificación hidrológica, registro de aguas, medición fiable de los consumos de agua, etc.); e incluso se ocupa de añadir nuevas técnicas, nuevos medios dirigidos a aumentar la masa hídrica disponible ${ }^{41}$.

Pero, como antes se dijo, es en lo relativo a la perspectiva ecológica donde se aprecia la recepción por el legislador español de la nueva filosofía comunitaria - tan tenuemente expresada de inicio como ya vimos- y de un modo muy explícito y visible. En efecto, donde la Ley de Aguas de 1985 decía que «la planificación hidrológica tendrá por objetivos generales conseguir la mayor satisfacción de las demandas de agua y equilibrar y armonizar el desarrollo regional y sectorial, incrementando las disponibilidades del recurso, protegiendo su calidad, economizando su empleo y racionalizando sus usos en armonía con el medio ambiente y los demás recursos naturales» (art. 38.1), el precepto de la Ley 46/1999 que lo reforma altera la prelación de los objetivos, colocando en primer lugar "el buen estado ecológico del dominio público hidráulico» y a continuación, por su mismo orden, los que figuraban en el artículo reformado, antes transcrito.

No es esta la única manifestación que hace la ley reformadora de su nuevo punto de mira, pues en su propia exposición de motivos, al hablar de los vertidos, hace referencia - ahora sí- a la normativa europea, subrayando que las mayores exigencias que imponen tanto dicha normativa «como la propia sensibilidad de la sociedad española», demandan, en definitiva, la adopción de dos técnicas concretas: a) regulación más estricta de las autorizaciones de vertidos; b) regulación de

${ }^{41}$ Medidas tales como la demanialización de las aguas procedentes de desalación; inclusión en el dominio público de las charcas, antes excluidas de esta clase de bienes. Asimismo, se ocupa de la reutilización de aguas depuradas — cuya incipiente regulación ya figuraba en la Ley de Aguas de 1985-, así como los contratos de cesión de derechos de aguas con su correlativa flexibilización del régimen concesional. Incide de manera frontal sobre la obra hidráulica, carente de una regulación especial como modalidad singular y específica de la obra pública, y del régimen económico y financiero. En fin, regulaciones todas ellas plenamente autóctonas, como lo corrobora el hecho de que la Ley de 1999 no haga la menor alusión a normativa europea alguna relacionada con dichas materias; y es que, en verdad, ninguna se había dictado hasta entonces sobre tales aspectos. 
los caudales ecológicos como restricción general a todos los sistemas de explotación.

En suma, la Ley 46/1999 de reforma de la Ley de Aguas realza entre sus objetivos el de "alcanzar el buen estado de las masas de agua», como sería reconocido luego por la Ley 10/2001 de 5 de julio del Plan Hidrológico Nacional; Ley ésta - dictada año y medio después de la comentada Ley 46/1999- que desde la óptica del derecho español de aguas que venimos denominando endógeno, es la que culmina el proceso de planificación hidrológica ya iniciado con el desarrollo y aprobación de los planes hidrológicos de cuenca en 1998 y la elaboración del Libro Blanco del Agua en el año 2000.

El objeto fundamental de la Ley del Plan Hidrológico Nacional son los transvases y ello, como es lógico, abre un amplísimo capítulo con sustantividad propia que no trae causa directa de la normativa europea sino que se engendra por las propias exigencias que manan de la forma de ser del elemento mismo, como venimos repitiendo, y que la exposición de motivos de la Ley expone en los términos más sencillos: «En un país como España en el que el agua es un recurso escaso, marcado por graves desequilibrios hídricos debido a su irregular distribución, la adecuada planificación de la política hidráulica se impone como una necesidad que no puede permanecer ajena a esta realidad...»

Pues bien, pese a esta estrecha vinculación material entre esta Ley 10/2001 del PHN y los preexistentes planes hidrológicos de cuenca y el tema de los transvases, esta no pierde la oportunidad de conectar con esa "perspectiva ecológica», ya emergente, reconociendo en la planificación un instrumento idóneo para alcanzar un buen estado ecológico de las aguas. No puede ser más clara la exposición de motivos de la Ley en lo tocante a este punto: «Esta planificación no puede entenderse en nuestros días sin que el medio ambiente sea la principal referencia de su contenido». Es más, pese al carácter eminentemente autóctono del objeto abordado por la Ley del Plan Hidrológico Nacional, la propia Ley subraya con todo énfasis que esta se dicta habiendo aparecido ya la nueva «Directiva Marco» ${ }^{42}$, porque «el presente Plan Hidrológico Nacional no puede permanecer indiferente a la reciente aprobación de la Directiva 2000/60/CE... por lo que hace suyos sus principios esenciales», destacando incluso cuáles son los puntos de la filosofía de la Directiva que se incorporan a nuestro derecho de aguas: a) el principio de recuperación

42 Directiva 2000/60 del Parlamento de la EU y del Consejo, de 23 de octubre, estableciendo el marco de actuación comunitario en el ámbito de la política de aguas. Como puede observarse, esta Directiva surge en el breve intervalo temporal existente entre la Ley 46/1999 de reforma de la Ley de Aguas y la Ley 10/2001 del PHN. 
de costes; b) la participación de la sociedad en el proceso de elaboración del Plan Hidrológico Nacional; c) la garantía del acceso a la información en materia de aguas». La incorporación de dichos principios a nuestro derecho interno, recibidos por vía de la Ley del Plan Hidrológico, como se ha dicho, quedó consolidada, por si alguna falta hacía, quince días después en el nuevo Texto Refundido de la Ley de Aguas, R.D. Legislativo $1 / 2001$ de 20 julio.

Como la presente exposición ha de ser consecuente con la premisa de partida de que debe circunscribirse a depurar la influencia real de la normativa europea sobre el derecho español de aguas, sin detenerse en otros asuntos, (por ejemplo, los transvases, entre otros diversos), ello conduce derechamente a examinar los problemas concernidos desde la atalaya que representa la Directiva Marco 2000/60. Desde ella podremos divisar el panorama con mayor perspectiva para poder así inventariar los genuinos impactos de las normas europeas sobre nuestro derecho de aguas.

V. La Directiva Marco 2000/60. La ordenación de las aguas desde una PERSPECTIVA GENERAL, INCLUIDO EL ÁMBITO MARINO Y EL MEDIO AMBIENTE

Un primer dato a resaltar por su enorme importancia, y desde luego decisivo para el fin aquí pretendido, es el hecho de que la Directiva Marco aborda temas antes inéditos en la Unión Europea siendo su espectro tan amplio que prácticamente se conectan con cualquier regulación «endógena» anterior de nuestro derecho de aguas propio. Es muestra bien expresiva de esta nueva perspectiva integral de la ordenación de la materia la directiva que se ocupa de la evaluación y gestión de riesgos de inundación ${ }^{43}$, y especialmente destacable es que su influencia abarca incluso a los vertidos marinos, al objeto de «interrumpir o suprimir gradualmente los vertidos, las emisiones y las pérdidas de sustancias peligrosas prioritarias ${ }^{44}$. En fin, su incidencia sobre tantos aspectos de la materia complica la visión del panorama normativo en el sentido de que dificulta discernir entre lo que es derecho nacido como fruto de nuestra propia evolución interna y lo que son regulaciones o técnicas que derivan de normas creadas por la Unión Europea. Basta contemplar

43 Directiva del Parlamento y del Consejo 2007/60 de 23 de octubre, transpuesta por el RD 903/2010 de 9 de julio. Los Planes han sido aprobados a lo largo de los primeros meses de 2016.

44 Art. 108-bis del T.R. de la Ley de Aguas. Es fundamental tener en cuenta al respecto la Directiva 2008/56 sobre estrategia marina y la Ley 41/2010 de Protección del Medio Marino, así como los estudios que de ello se hacen en E. Arana García y F. J. SAnz Larruga (dirs.) (2012), La ordenación jurídica del medio marino en España, Cizur Menor: Civitas-Thomson-Reuters. 
el Anexo VI de la Directiva en el que se contiene la «lista de las medidas que deben incluirse en los Programas" como objetivos a cumplir en el seno de las demarcaciones hidrográficas, para percatarse de que el elenco abarca desde aquellas primigenias medidas "sanitarias» que fueron adoptadas por la $\mathrm{CEE}$ en su primera andadura hasta las técnicas actuales surgidas a impulso de las nuevas demandas y necesidades del sector; por cierto, técnicas algunas de las cuales ya habían sido inauguradas motu proprio por el legislador español (protección de humedales, controles de vertidos, plantas de desalinización, reutilización de aguas depuradas...).

Sentado lo anterior, obligado es resaltar, aunque con suma concisión en este caso, el objeto de la Directiva, los principios que la animan, así como sus principales contenidos.

En cuanto al objeto, su artículo 1 proclama que es establecer un marco para la protección de las aguas de transición ${ }^{45}$, las $\operatorname{costeras~}^{46}$ y subterráneas, con el fin de prevenir todo deterioro adicional y proteger y mejorar el estado de los sistemas acuáticos y sus ecosistemas dependientes; promover un uso sostenible del agua, reducir progresivamente los vertidos y la contaminación del agua subterránea, paliar los efectos de las inundaciones y sequías; todo ello con el fin de garantizar el suministro suficiente de agua superficial o subterránea en buen estado, reducir la contaminación de las aguas subterráneas, proteger las aguas territoriales y marinas y prevenir y erradicar la contaminación del medio ambiente marino.

Respecto a los principios, el artículo 1, cuyo extracto se acaba de exponer, viene a ser el condensado de los numerosos «considerandos» que le preceden, en los que la Directiva expresa su filosofía sobre la materia. Siendo imposible dejar aquí constancia de todos ellos, queden citados algunos que ponen vivamente de manifiesto la visión integradora de la que parte la Directiva o, más exactamente, su consciencia permanente de la interrelación de los factores que concurren en el elemento «agua». Así, cuando se afirma — considerando 17- que: «Una política de aguas eficaz y coherente debe tener en cuenta la vulnerabilidad de los sistemas acuáticos situados cerca de las costas y los estuarios o los golfos o mares relativamente cerrados, puesto que el equilibrio de todas estas zonas de-

45 Definidas por el art. 2.6) de la Directiva: «masas de agua superficial próximas a la desembocadura de los ríos que son parcialmente salinas como consecuencia de su proximidad a la aguas costeras, pero que reciben una notable influencia de flujos de agua dulce».

46 Definidas por el art. 2.7) de la Directiva: «aguas superficiales situadas hacia tierra desde una línea cuya totalidad de puntos se encuentra a una distancia de una milla náutica mar adentro desde el punto más próximo de la línea de base que sirve para medir la anchura de las aguas territoriales y que se extienden, en su caso, hasta el límite exterior de las aguas de transición». 
pende en buena medida de la calidad de las aguas continentales que fluyen hacia ellas»; o en cuanto a la simbiosis "cantidad-calidad», tensión ya referida supra en estas mismas páginas, la Directiva - Considerando 19- se decanta por el factor calidad; y prolonga la misma idea respecto a la interrelación «superficiales-subterráneas» (Considerando 20). Todo lo cual ha de entenderse como perfectamente lógico y casi sobrado de explicación pues, al cabo, la finalidad primera y última - alfa y omegano es otra que la expresada con toda sencillez en el Considerando 24: "La buena calidad del agua contribuirá a garantizar el abastecimiento de agua potable a la población».

En cuanto a su contenido, dado el abigarrado panorama que la Directiva ofrece, resulta necesario partir al menos de la distinción entre su parte orgánica y la dedicada a los aspectos sustantivos.

\section{La demarcación hidrográfica como organización.}

Demarcación hidrográfica es «la zona marina y terrestre compuesta por una o varias cuencas hidrográficas vecinas y las aguas subterráneas y costeras asociadas, designada con arreglo al apartado 1 del artículo 3 como principal unidad a efectos de la gestión de las cuencas hidrográficas» (art. 2.19). Dispone el artículo 13 de la Directiva que «los Estados miembros velarán porque se elabore un plan hidrológico de cuenca para cada demarcación hidrográfica situada totalmente en su territorio; y seguidamente el propio artículo aborda el supuesto de la demarcación hidrográfica internacional ${ }^{47}$.

Hay que tener en cuenta que la unidad física y jurídica de referencia es la demarcación ${ }^{48}$; por ello, el concepto tradicional de la «cuenca hidrográfica» con el que había venido operando el derecho español de aguas y que aún define la Directiva Marco como «la superficie de terreno cuya escorrentía superficial fluye en su totalidad a través de una serie de corrientes, ríos y, eventualmente, lagos hacia el mar por una

47 2. En el caso de una demarcación hidrográfica internacional situada totalmente en territorio comunitario, los Estados miembros garantizarán la coordinación con objeto de elaborar un único plan hidrológico de cuenca internacional. Si no se elabora dicho plan hidrológico de cuenca internacional, los Estados miembros elaborarán planes hidrológicos de cuenca que abarquen al menos las partes de la demarcación hidrográfica internacional situadas en su territorio, para lograr los objetivos de la presente Directiva.

48 Así resulta claramente del artículo 3 de la Directiva cuando dispone que: «Los Estados miembros especificarán las cuencas hidrográficas situadas en su territorio nacional y, a los efectos de la presente Directiva, las incluirán en demarcaciones hidrográficas. Las cuencas hidrográficas pequeñas podrán, en su caso, combinarse con cuencas más grandes o agruparse con pequeñas cuencas hidrográficas vecinas para formar una demarcación hidrográfica». 
única desembocadura, estuario o delta» (art. 2.13), no deja de ser una realidad física identificable pero carente ya de entidad jurídica de peso, de tal modo que los «planes hidrológicos de cuenca» de los que trata el artículo 13 de la Directiva Marco no tienen por objeto ese tradicional concepto, sino la demarcación entera. Por tanto, se opta por un principio de unicidad y globalidad del plan que rebasa, si ello resulta preciso, los límites propios de la cuenca «clásica»; es más, la Directiva extiende tal principio incluso a las demarcaciones hidrográficas internacionales, si afectan a territorio comunitario sea total o parcialmente (art. 13.2).

A la vista de lo expuesto no es preciso ponderar la ambición integradora de la demarcación hidrográfica y su plan hidrológico de cuenca conforme al nuevo concepto de ésta, así como su virtud superadora de fronteras políticas y artificiales. Ello ha supuesto una aplicación de la misma no exenta de dificultades, como revelan las sentencias dictadas por el TJUE sobre incumplimientos por los Estados miembros; y precisamente por ello, su aplicación a España no sólo ha tenido la dimensión hidrológica — científica, técnica, medioambiental-que le es propia, sino que llevaba consigo la dificultad añadida de su percusión sobre un sistema fuertemente descentralizado y beligerante en grado sumo en lo tocante a las competencias, con un mapa físico compuesto por aguas intracomunitarias e intercomunitarias reconocidas por la Constitución a efecto del reparto de la materia entre las comunidades autónomas y el Estado. Ello provocó ciertos conflictos focalizados en las cuencas intracomunitarias valencianas y murcianas, referidos, en síntesis, a la posibilidad o no de incluir tales cuencas en las intercomunitarias del Júcar y del Segura ${ }^{49}$, cuestión que finalmente fue zanjada por la STC 149/1912 de 5 julio en el sentido de que no pueden incluirse cuencas de competencia autonómica en las demarcaciones hidrográficas del Estado.

Pero especial atención merecen los conflictos relacionados con el Duero y el Guadalquivir. El telón de fondo de la cuestión está en la mente de todos y no es preciso descender al análisis del reparto constitucional de competencias (arts. 148.1.10 y 149.1.22 ${ }^{\mathrm{a}} \mathrm{CE}$ ). La superficie ocupada por las cuencas intercomunitarias peninsulares alcanza el 87 por ciento frente al 13 por ciento de las intracomunitarias. La disputa sobre las primeras estaba servida. Surgió la Ley de Aguas de 1985 con su definición del concepto de cuenca (art. 14), así como la STC 227/1988 que dio pleno respaldo a la solución legal. Tanto una como otra disiparon cualquier duda sobre el concepto de cuenca que había que manejar, descartando que pudieran tomarse como referencia los cauces aislados, conclusión

49 SSTS de 20 de octubre de 2004 y 22 y 27 de septiembre de 2011. 
que es la plasmada en el Texto Refundido de la Ley de Aguas ${ }^{50}$, siguiendo en este punto las recomendaciones contenidas en la Carta del Agua y el Plan de Acción del Mar del Plata. Las cuencas intercomunitarias resultantes fueron nueve ${ }^{51}$; ya quedaron referenciados supra los Reales Decretos que crearon sus respectivos organismos de cuenca.

Como es bien sabido algunos Estatutos autonómicos de la hornada iniciada en 2006 aspiraron a romper el statu quo sobre las cuencas - debate siempre encendido, hay que decirlo- bien en el sentido activo de reivindicar para sí el derecho a las aguas sitas en comunidad autónoma vecina (casos de Andalucía y Castilla y León), o bien en el defensivo de impedir el transvase de «sus» aguas a otros territorios (Aragón, Castilla-La Mancha y Castilla y León) ${ }^{52}$. Pues bien, en lo que atañe al primer aspecto que es lo que importa en el marco del presente estudio, hay que concluir señalando: a) que los dos Estatutos citados (Andalucía, art. 51 y Castilla y León, art. 75) eran contrarios a una legalidad que fue respaldada por el Tribunal Constitucional, por más que de contrario se invocaran argumentos que cuestionaban la racionalidad de que la gestión hubiera de regirse necesariamente por el principio de unidad de cuenca; b) que antes de que el TC emitiera su sentencia sobre el «reto» autonómico planteado, el Gobierno de la Nación formalizó con la Junta de Andalucía -12 de noviembre de 2007- el Acuerdo inicial sobre la transferencia del río Guadalquivir ${ }^{53}$; c) que el TC, mediante sus Sentencias 30 y 31/2011 de 16 y 17 de marzo declaró la inconstitucionalidad de los citados preceptos, lo que a la postre supuso, en el caso del Guadalquivir, la devolución al Estado de todas las transferencias recibidas por la Junta de Andalucía.

En verdad es hasta chocante la paradoja de que la pequeña-gran historia que se acaba de reseñar coincidiera en el tiempo con la aparición

50 Art. 16, redactado por el artículo 129.6 de la Ley 62/2003 de 30 de diciembre que incorpora la Directiva Marco 2000/60.

51 Duero, Ebro, Tajo, Guadiana, Júcar, Segura, Guadalquivir, Miño-Limia y las supracomunitarias integradas en la Confederación Hidrográfica del Norte. Para una visión completa del mapa hidrográfico de España desde el ángulo jurídico constitucional puede verse F. LóPEz Menudo (2008), «Agua y Territorio», en Informe sobre Comunidades Autónomas 2007 (págs. 57 y ss.), Barcelona: Instituto de Derecho Público.

52 Para los pormenores de toda esta conflictividad, vid. ibid. y la monografía de A. GArrorena Morales y A. Fanlo Loras (2008), La constitucionalidad de los nuevos Estatutos en materia de aguas, Murcia: Fundación del Instituto Euromediterráneo del Agua.

53 Acuerdo firmado en lugar tan simbólico como el Parador de Cazorla —nacimiento del Guadalquivir-, calificado de histórico por los suscribientes del mismo, la ministra dña. Elena Salgado y el consejero de Presidencia don Gaspar Zarrías, quienes llegaron a vaticinar que el Acuerdo suscrito serviría de modelo para otras comunidades autónomas. Sin poder detallar aquí los avatares que sucedieron luego, valga el dato reseñado en el texto: el final de la historia se saldó con la devolución al Estado de la totalidad de las competencias traspasadas (RD 1498/2011 de 21 octubre). 
de la Directiva Marco 2000/60. En efecto, aquel pulso sobre el tema de las cuencas empezó formalmente a rodar en el mes de junio de $2001^{54}$ siendo así que dicha Directiva - que era vox populi desde mucho antes de su aprobación - fue publicada en el DOCE el 22 de diciembre de 2000 y claramente indicaba el camino a seguir. Pese a todo, el conflicto fue virulento y quedó escenificado y exprimido hasta su último extremo, como queda relatado.

Por tanto, fueron desarrollándose dos historias paralelas: la de la trifulca sobre el tema de las cuencas y la del proceso de asentamiento y desarrollo de la Directiva Marco que conducía derechamente a una solución ya predeterminada, superadora del debate que se planteaba por las referidas comunidades autónomas. Así, la Directiva 2000/60 ya había dejado su primera huella el 5 de julio de 2001 en el Plan Hidrológico Nacional, como ha quedado dicho supra; en diciembre de 2003 la Directiva quedó incorporada al derecho español ${ }^{55}$; su principio relativo a la preservación de caudales ecológicos circulantes justificó en buena parte la reforma en 2005 de la Ley del Plan Hidrológico Nacional ${ }^{56}$; seguidamente, a comienzos de 2007, las demarcaciones se materializan ya como organismos para la gestión del agua, como se verá en seguida; y la propia figura de la demarcación hidrográfica proyecta finalmente su potente presencia en las dos sentencias constitucionales de 2011 antes citadas, que anularon en este punto los Estatutos de Andalucía y de Castilla y León a instancia del Gobierno de la Junta de Extremadura.

Es el Decreto 125/2007 de 2 de febrero el que fija el ámbito territorial de las demarcaciones hidrográficas y por ende el de su respectivo plan hidrológico. Se opta por mantener, en la medida de lo posible, la estructura preexistente de cuencas hidrográficas más la adición de las aguas de transición y las costeras ${ }^{57}$. Pues bien, de ello ha resultado el mapa siguiente: demarcaciones intercomunitarias sitas solamente en territorio español (Guadalquivir, Júcar y Segura); las intercomunitarias compartidas con otros países (Cantábrico Oriental, Duero, Ebro, Guadiana, Miño-Sil,

54 Precisamente en el seno del debate sobre el estado de la Comunidad Autónoma de Andalucía y con ocasión de celebrarse el XX aniversario del Estatuto de 1981. Hemos relatado estos antecedentes en "Comentarios al art. 51» (2008), del libro de S. Muñoz Machado y M. Rebollo Puig (dirs.), Comentarios al Estatuto de Autonomía para Andalucía (pág. 471), Cizur Menor: Cívitas-Thomson.

55 Ley 62/2003 de 30 de diciembre de medidas fiscales, administrativas y del orden social, cuyo art. 129 modificó numerosos artículos del TR de la Ley de Aguas (RD Legislativo 1/2001 de 20 de julio).

56 Ley 11/2005 de 22 de junio (BOE 149 de 23 de junio).

57 El RD, cuya última modificación fue introducida por el RD de 29 de agosto de 2015, añade otras precisiones sobre las aguas subterráneas y de las cuencas compartidas con países vecinos. Cabe anotar en este punto la STJUE de 7 de mayo de 2009 relativa a la delimitación de ciertas demarcaciones hidrológicas y la designación de las autoridades competentes. 
Tajo, a las que hay que añadir Ceuta y Melilla). Intracomunitarias (Galicia-costa, Cuenca fluvial de Cataluña, Cuencas mediterráneas andaluzas, Guadalete y Barbate, Tinto-Odiel-Piedras, Islas Baleares y demarcaciones hidrográficas de las distintas islas Canarias). Las intercomunitarias son de la titularidad de la Administración General del Estado, y están participadas por las Administraciones autonómicas y locales afectadas, siendo su órgano de gestión —al menos nominalmente- el Comité de Autoridades Competentes, pues sus competencias son fundamentalmente de cooperación y consultivas ${ }^{58}$; y las intracomunitarias son de la competencia y gestión de la respectiva Administración hidráulica autonómica.

\section{Directiva Marco y planificación hidrológica}

Antes quedaron señalados los propósitos de la Directiva, prolijamente relacionados en sus artículos de cabecera. Un rasgo a destacar es que tras esa "parte general» de la norma, como podría decirse en términos didácticos, no existe una "parte especial» a la vista de la cual pudiera hacerse una valoración analítica de cada tema concernido. Por tanto, es una metodología sui géneris la seguida por la Directiva Marco. Ciertamente, algunos de sus artículos versan «monográficamente» sobre aspectos concretos ${ }^{59}$; pero salvo dos artículos de la Directiva dedicados a anunciar las estrategias y medidas a adoptar para combatir la contaminación de las aguas superficiales y las subterráneas (arts. 16 y 17, respectivamente), toda ella vierte prácticamente su contenido en la prevalente figura del «Plan Hidrológico de Cuenca». Prácticamente, todos los aspectos sustantivos referidos a las aguas son para ser implantados, establecidos, enunciados o valorados en el seno de cada demarcación hidrográfica y por su instrumento, el plan, que opera así como el gran recipiente en el que han de contenerse todas las medidas, previsiones, programas, etc., sobre todo tipo de aguas y sus distintas finalidades. Ciertamente, dos instituciones jurídicas — demarcación y plan- en puridad nada nuevas sino que amplifican, o recrean si se quiere, figuras que ya existían de antiguo en el derecho español.

58 El RD. 126/2007 de 2 de febrero regula la composición, funcionamiento y atribuciones de los comités de autoridades competentes de esas demarcaciones hidrográficas con cuencas intercomunitarias (modificado por RD de 8 diciembre 2011). Y una serie de RR DD dictados en el último trimestre de 2011 (en 2013 en los casos del Júcar, Ceuta y Melilla) crearon los respectivos Consejos del Agua como órganos de participación y planificación ya previstos en el TR de la Ley de Aguas de 2001 (arts. 26 y 35).

59 Registro de zonas protegidas (art. 6), aguas destinadas al consumo humano (art. 7), seguimiento del estado de las aguas superficiales, del estado de las aguas subterráneas y de las zonas protegidas (art. 8), recuperación de los costes de los servicios relacionados con el agua (art. 9), programas de medidas (art. 11). 
De este modo, el derecho europeo sobre aguas deja de estar constituido por un rosario de disposiciones singulares creadas por goteo, para convertirse en una especie de derecho globalizado que se infiltra por todos los poros de los sistemas jurídicos referidos al agua, llegando a todos sus rincones, al cabo, por vía de la planificación hidrológica.

Así, la Directiva 2000/60 erige cada demarcación hidrográfica como el marco en el que ha de funcionar el registro o registros de zonas declaradas de protección especial en virtud de una norma comunitaria específica (art. 6) y para el señalamiento de las aguas destinadas al consumo humano (art. 7) o para el seguimiento del estado de las aguas superficiales, subterráneas o de las zonas protegidas (art. 8), o la regulación de los costes de los servicios, incluidos los medioambientales y los relativos a los recursos, de acuerdo con el principio de «quien contamina paga» (art. 9).

Pero aún más importantes, si cabe, son, de una parte, el llamado «Programa de medidas» al que se refiere su denso artículo 11 que distingue entre las «básicas» o requisitos mínimos que deberán contemplarse y las «complementarias» para el logro de objetivos adicionales. La trascendencia de este "Programa» resulta bien clara a la vista del Anexo VI, donde figura la lista de las medidas que en aquél deben incluirse, entre las que figuran precisamente las que son objeto de las dictadas por la UE en esta materia (aguas de baño, consumo humano, residuales urbanos, nitratos...) a las que se añaden otras referidas al medio ambiente (evaluación sobre el impacto ambiental, aves silvestres, hábitats naturales); todo lo cual supone, por una parte, un cierto efecto codificador de la normativa incidente sobre la materia y, por otra, viene a patentizar la íntima interrelación existente entre las aguas y el medio ambiente como un todo inseparable por naturaleza. De otro lado, ocioso es destacar de nuevo, a estas alturas del relato, la tan relevante figura del plan hidrológico de cuenca perfilada por el artículo 13, así como el listado de las determinaciones que ha de contener según prescribe el Anexo VII, con lo que, como es fácil de colegir, queda convertido en un instrumento de una fuerza directiva y coordinadora verdaderamente espectacular, llegando incluso a dotar al complejo mapa hídrico europeo de una isomorfía difícilmente concebible a priori, dada la heterogeneidad del sustrato material sobre el que opera, lo que no quiere decir que sea idéntica la naturaleza jurídica de la planificación adoptada en cada Estado.

Por lo que a España concierne, ya quedó anotada supra la recepción de la Directiva y su plasmación a grandes rasgos en el TR Ley de Aguas (fundamentalmente en los artículos 40 a 42). Pero la verdadera pieza maestra del sistema no es otra que el Reglamento de la Planifica- 
ción Hidrológica ${ }^{60}$, una disposición que profundiza en los detalles de la Directiva, ordena meticulosamente sus determinaciones y se vertebra con regulaciones aledañas a la materia, tales como la normativa sobre evaluación de impacto ambiental y las zonas de protección de hábitats o especies relacionadas con la Red Natura 2000 y las tan destacables directivas 92/43/CEE y 79/409/CEE.

Ofrece, pues, dicho Reglamento, dotado de una notable cantidad de preceptos que tienen el carácter de normativa básica estatal (lo que importa especialmente por lo que atañe a las cuencas intracomunitarias) una especie de vademécum pletórico de información y de una virtud ordenadora desusada, si por añadidura se tienen en cuenta sus previsiones sobre la elaboración y aprobación de los propios planes. Si a todo ello se añade la Instrucción de Planificación Hidrológica ${ }^{61}$, con su desarrolladísimo índice o patrón para confeccionar los planes, ello explica la extraordinaria homogeneidad del conjunto estatal resultante, es decir, la excepcional similitud que ofrecen los planes hidrológicos aprobados al menos en su estructura y en la ordenación de sus epígrafes principales, con independencia del tipo de cuenca de que se trate. A este esquema responden tanto los planes aprobados ahora llamados del "primer ciclo» ${ }^{62}$ como los planes renovados o de "segundo ciclo» aprobados recientemente por el Real Decreto 1/2016 de 8 de enero, cuyo rico preámbulo proclama entre otros aspectos de mucho interés que la planificación hidrológica española aporta ahora una visión más completa e integradora de lo que debe ser la gestión de las aguas, aunando los aspectos de protección y recuperación ambiental con los de utilización y aprovechamiento del recurso, todo ello en el marco de los tres ejes sobre los que se desarrolla la Directiva Marco: sostenibilidad ambiental, racionalidad económica y transparencia y participación social.

\section{CONCLUSIÓN}

Desde el punto de vista cuantitativo, el derecho europeo sobre aguas ha alcanzado una dimensión considerable, máxime teniendo en cuenta

\footnotetext{
60 RD 907/2007 de 6 de julio.

61 Orden del Ministerio de Medio Ambiente, Medio Rural y Marino 2656/2008 de 10 septiembre (BOE, 229, de 22 de septiembre).

62 Por orden cronológico, RRDD 1329/2012 (Tinto-Odiel-Piedras), 1330/2012 (Guadalete y Barbate), 1331/2012 (Cuencas Mediterráneas Andaluzas), 1332/2012 (Galicia-Costa), 285/2013 (Miño-Sil), 354/2013 (Guadiana), 355/2013 (Guadalquivir), 399/2013 (Cantábrico Occidental), 400/2013 (Cantábrico Oriental), 478/2013 (Duero), 739/2013 (Ceuta), 740/2013 (Melilla), 129/2014 (Ebro), 270/2014 (Tajo), 594/2014 (Segura), 595/2014 (Júcar), 701/2015 (Islas Baleares). Estos Planes tendrían que haber sido aprobados antes del 22 de diciembre de 2009; el retraso motivó la STJUE condenatoria de 4 de octubre de 2012 (C-403/11).
} 
que en su proceso de desarrollo ha ido vinculándose con otras áreas (medio ambiente, medio marino, etc.) que no se integraban en principio en el concepto jurídico de las «aguas continentales». Es una realidad que esa normativa ha acabado extendiéndose como una mancha de aceite, lenta e implacablemente, impregnando de arriba abajo, con más o menos dificultades, todo nuestro derecho de aguas.

Sin embargo, ante este fenómeno no cabe asombrarse, pues el «asombro" sólo lo produce lo inesperado y es un hecho que las instituciones y técnicas del derecho europeo ya eran conocidas por nuestro viejo derecho sobre la materia. Tampoco cabe el triunfalismo, pues existen objetivos de la Directiva 2000/60 aún no satisfechos debidamente (principio de recuperación de costes, mayor participación ciudadana en la elaboración de los planes...) y subsisten las dificultades para implantar un patrón, con grado de rigidez que ha de tenerse como inevitable, a una realidad absolutamente heterogénea, cosa esta que es predicable de todos los Estados de la Unión.

Pero lo anterior no impide hacer una valoración positiva, o muy positiva, de esa normativa y su repercusión sobre nuestro derecho interno pues ha supuesto, además de la lógica mejora de algo tan íntimamente ligado a la salud, al bienestar y a los intereses públicos y privados, la introducción de un factor o poder «disciplinante» — permítase la expresión- de una trascendencia política de primera magnitud. Basta echar la vista atrás y recordar ciertos episodios en los que ha quedado probado el espíritu dispersor que esta nuestra sociedad lleva dentro; sucesos en los que ha primado el afán por la victoria política puntual, frente a la apuesta por la racionalidad de un sistema general; o comportamientos surgidos en angustiosos momentos de sequía que han permitido ver que la tan cacareada solidaridad puede ser solamente un nombre y que la demagogia es, en cambio, algo que existe realmente. Dos verdaderos venenos que lamentablemente anidamos aquí y que fueron disueltos en su día, más que por las normas dictadas entonces a la desesperada, por las salutíferas lluvias que inesperadas y ubérrimas cayeron del cielo —ahora sí- ante el asombro general. Actualmente, transcurridos ya más de diez años desde aquella situación, contamos con unos instrumentos jurídicos más capaces de coadyuvar a resolver unas circunstancias similares, aunque, desde luego, hay que rogar porque no se repitan. Por tanto, aunque diga el dicho que «nunca llueve a gusto de todos», habrá que responder: sí, pero es mejor que lo haga... Siempre será más fácil luchar contra la abundancia que contra la escasez. 